Popovych Igor L., Gozhenko Anatoliy I., Badiuk Nataliya S., Napierała Marek, Muszkieta Radosław, Zukow Walery, Yanchij Roman I., Lapovets' Natalia Ye., Lapovets' Lyubov Ye., Tserkovnyuk Ruslan G., Akimova Viorica M., Nahurna Yaryna V., Martianova Olha I., Vivchar Roman Ya., Chendey Ivanna V., Ruzhylo Sofiya V. Relationships between geomagnetic Ap-index and parameters of the immunity in patients with multiple sclerosis and radiculopathies. Journal of Education, Health and Sport. 2021;11(3):77-90. eISSN 2391-8306. DOI http://dx.doi.org/10.12775/JEHS.2021.11.03.009 https://apcz.umk.pl/czasopisma/index.php/JEHS/article/view/JEHS.2021.11.03.009 https://zenodo.org/record $/ 4636917$

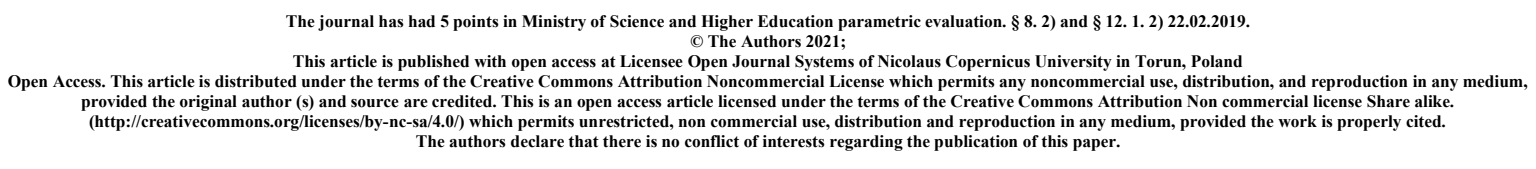

Received: 15.02.2021. Revised: 26.02.2021. Accepted: 25.03.2021.

\title{
Relationships between geomagnetic Ap-index and parameters of the immunity in patients with multiple sclerosis and radiculopathies
}

Igor L. Popovych ${ }^{1}$, Anatoliy I. Gozhenko ${ }^{2}$, Nataliya S. Badiuk ${ }^{3}$, Marek Napierała ${ }^{4}$, Radosław Muszkieta ${ }^{5}$, Walery Zukow', Roman I. Yanchij,', Natalia Ye. Lapovets', Lyubov Ye. Lapovets', Ruslan G. Tserkovnyuk ${ }^{10}$, Viorica M. Akimova ${ }^{11}$, Yaryna V. Nahurna ${ }^{12}$, Olha I. Martianova ${ }^{13}$, Roman Ya. Vivchar ${ }^{14}$, Ivanna V. Chendey ${ }^{15}$, Sofiya V. Ruzhylo ${ }^{16}$

${ }^{1,2,3,10}$ State Enterprise Ukrainian Research Institute for Medicine of Transport, Ministry of Health of Ukraine, Odesa, UKRAINE

${ }^{4}$ University of Economy, Bydgoszcz, POLAND

${ }^{5,6}$ Nicolaus Copernicus University, Torun, POLAND

${ }^{1,7}$ OO Bohomolets' Institute of Physiology, Kyïv, UKRAINE

8,9,11,12,13,14,15 Danylo Halyts'ky̌̌ National Medical University, L’viv, UKRAINE

${ }^{16}$ Ivan Franko Pedagogical University, Drohobych, UKRAINE

Corresponding Author Walery Zukow E-mail: w.zukow@wp.pl

\begin{abstract}
Background. The effect of geomagnetism on human immunity has so far been studied through long-term observations. We set ourselves the goal of detecting the immediate immunotropic effects of the Earth's magnetic field by analyzing the relationships between immunity parameters and the geomagnetic Ap-index. Material and methods. The object of observation were 74 patients with multiple sclerosis and 14 patients with radiculopathies, who in the period from September 2014 to November 2018 conducted a one-time assessment of immune status by the relative content in the blood of lymphocytes of $\mathrm{CD}^{+}, \mathrm{CD} 4^{+}, \mathrm{CD} 8^{+}, \mathrm{CD} 25^{+}, \mathrm{CD} 56^{+}$and $\mathrm{CD} 19^{+}$phenotypes and serum level of Immunoglobulines M, G, A as well as CIC and IL-1 $\beta$. On the day of blood capture and during the previous 7 days, retrospectively recorded the geomagnetic Ap-index, using a publicly available information resource http://wdc.kugi.kyoto-u.ac.jp/kp/index.html. Results. During the week, the average level of Ap-index ranged from $12 \div 20 \mathrm{nT}$. The correlation coefficients between the Ap-index on the day of blood collection and 1 , 3 and 7 days before it and the level of $\mathrm{CD}^{+} \mathrm{CD}^{+}$lymphocytes were $-0,57 ;-0,48 ;-0,55$ i $-0,52$ respectively, while on other days were in the range of $-0,35 \div 0,05$. In contrast, with the level of CD56 lymphocytes Ap-index correlates positively and almost mirror $(0,56 ; 0,43 ; 0,54$ i 0,57 respectively and $0,34 \div-0,08)$, due to the reciprocity of their levels $(\mathrm{r}=-0,80)$. Also positive, but much weaker, correlates the Ap-index with the level of CD25 lymphocytes $(0,35 ; 0,25 ; 0,45$ i 0,31 respectively and $0,22 \div-0,14)$. In contrast, with the level of IL- $1 \beta$ Ap-index correlates significantly only on the day of blood collection and 2 days before $(r=0,21$ and 0,31 respectively), and with other registered parameters of immunity the correlation is insignificant. The canonical correlation between Ap-indices for 7 days before and on the day of blood collection, on the one hand, and the levels of $\mathrm{CD}^{+}, \mathrm{CD} 6^{+}, \mathrm{CD} 25^{+}$and $\mathrm{CD}^{+}$lymphocytes and the concentration of IgM and IL-1 $\beta$ - on the other hand, was very strong: $\mathrm{R}=0,741 ; \mathrm{R}^{2}=0,549 ; \chi_{(42)}^{2}=130 ; \mathrm{p}<10^{-6}$. Conclusion. Disturbances of the geomagnetic field (Ap-index) has a significant immediate modulating effect on the level of immune parameters in the blood,
\end{abstract}


mostly T-helpers (suppressor) and natural killers (enhancing).

Key words: geomagnetic Ap-index; immune status; multiple sclerosis; radiculopathy.

We dedicate the article to the founder of Heliobiology Oleksandr Chyzhevsky, who inspired this study.

\section{Introduction}

In 1936, Russian scientist of Polish origin AL Chizhevsky concluded: "Life is a phenomenon... It lives due to dynamics; each oscillation of organic pulsation is coordinated with the Cosmic Heart in a grandiose Whole of Nebulas, Stars, the Sun and the planet". He suggested correlation of some biological processes on the Earth with cycles of Solar activity. But possible mechanisms of such interrelation are still not completely understood.

The posthumously published book of the founder of Heliobiology "The Cosmic Pulse of Life. The Earth is Embraced by the Sun. Heliotaraxia" inspired the first author to study the influence of geomagnetic factors on the human neuroendocrine-immune complex. This article is the first swallow of this project.

The geomagnetic field is a fundamental nature of the planet that is produced by the geodynamo of the Earth's outer core. All living beings live from birth to death in this field, and many species sense it and use it for navigation and immigration. There is evidence that changes in this field can affect biological systems (Zhadin, 2001; Gozhenko et al., 2018a; Gozhenko et al., 2018b). The presence of this field is vital for saving the atmosphere and the life on our planet from the dangerous particles of solar winds and cosmic radiations. While geomagnetic field deflects the solar wind particles, any changes in the density or the velocity of the solar wind interact with the magnetosphere and cause temporary alterations in the field that is measurable at the Earth surface (Dubrov, 2013). This phenomenon is called geomagnetic disturbance or geomagnetic activity.

The concept of space-weather is relatively new and the main researches about this phenomenon have been done in recent four decades (Hanslmeie, 2007). Moreover, as geomagnetic field and its disturbances are categorized as very low magnetic field without thermal and ionizing effect, their effects on physiological and pathophysiological issues, in comparison to other environmental factors, have generally been neglected by most biologists (Zhadin, 2001).

Space around our planet is not empty and the Earth is immersed in the solar energetic charged particles. Space-weather defined as the conditions in space that affect Earth, consequences of flowing ionized particle of the solar wind against geomagnetic field (Hanslmeier, 2007). However, geomagnetic field acts like a shield and deflect most of the solar charged particles, it is also impressed and altered by solar wind (Hanslmeier, 2007). These geomagnetic field alterations are called geomagnetic disturbances. For quantifying geomagnetic disturbances, several indices such as Planetary K index (Kp) and Planetary A index (Ap) were defined.

We know that some species sense geomagnetic field, probably by presence of magnetites, i.e. ferromagnetic particles in their central nervous system, and use it for orientation and migration (Zhadin, 2001). It was shown that human brain also contains magnetites (Kirschvink et al, 1992) and it was proposed that observed increases in stress hormones, heart rate, and the amount of myocardial infarctions during geomagnetic storms may induced by causing an adaptive stress reaction through the effect of geomagnetic disturbances on brain magnetosomes (Kirschvink et al, 1992a; Breus et al, 2008). Accordingly, histochemical finding about the presence of considerable iron deposits within myelin loops (LeVine et al, 2004) and evidences from imaging technics about increased iron deposits in subcortical gray matters of multiple sclerosis patients (Lebel et al, 2012), in addition to some results about greater incidence of cardiovascular diseases among multiple sclerosis patients (Christiansen et al, 2010), all may be regarded as indirect clues of a probable relation among the effects of geomagnetic disturbances on brain magnetosomes and pathogenesis of multiple sclerosis. However, it should be reminded that we don't know how amount of these iron deposits are in the form of magnetite.

There are evidences that adaptive immune system can be affected by very low magnetic field. Magnetic field as low as geomagnetic field can significantly change lymphocyte $\mathrm{Ca}^{2+}$ uptake (Walleczek, 1992). In addition, through three proposed mechanisms, geomagnetic field can change leukocyte behavior, activation and adhesion by inducing the membrane-mediated signal transduction cascades, like the time that a ligand-receptor interaction activates the cell (Jandova et al, 2005; Walleczek, 1992; Simko et al, 2004; Cocek et al, 2008). Those mechanisms include changes of ion flux, especially $\mathrm{Ca}^{2+}$ across cell membrane, cyclotron resonance and dissociation of protein-ion complex by changing quantum states of ions in their structures in the membrane proteins (Jandova et al, 2005). There are also evidences that magnetic fields can enhance release of reactive oxygen species by T cells and macrophages (Simko et al, 2004).

Sajedi and Abdollahi noticed that a hypothesis based on the effect of geomagnetic disturbances has the ability to explain special features of multiple sclerosis as autoimmune disease. The easiest way to evaluate hypothesis was to test the association of multiple sclerosis prevalence with angular distance to geomagnetic 60 degree latitude (AMAG60) and compare it with the known association of multiple sclerosis with geographical latitude. Authors did the same with angular distance to geographic 60 degree latitude (AGRAPH60) as a control. In each continent, AMAG60 had the best correlation with multiple sclerosis prevalence, the largest $\mathrm{AR}^{2}(0,47$; 
0,42 and 0,84 for Europe, North America and Australasia, respectively) and the least SEE. Merging both hemispheres data, AMAG60 explained $56 \%$ of multiple sclerosis prevalence variations with the least $\mathrm{SEE}(\mathrm{R}=$ 0,$\left.75 ; \mathrm{AR}^{2}=0,56 ; \mathrm{SEE}=57\right)$, while geographical latitude explained $17 \%\left(\mathrm{R}=0,41 ; \mathrm{AR}^{2}=0,17 ; \mathrm{SEE}=78,5\right)$ and AGRAPH60 explained $12 \%$ of that variations with the highest $\mathrm{SEE}\left(\mathrm{R}=0,35 ; \mathrm{AR}^{2}=0,12 ; \mathrm{SEE}=80,5\right)$. Obtained results confirmed that AMAG60 is the best describer of multiple sclerosis prevalence variations and has the strongest association with multiple sclerosis prevalence distribution (Sajedi and Abdollahi, 2012).

The aim of next study Abdollahi and Sajedi (2014) was to test probable correlation between solar activities and geomagnetic disturbances with long-term variations of multiple sclerosis incidence. Authors studied the association between alterations in the solar wind velocity $\left(V_{S W}\right)$ and planetary $A$ index $\left(A_{P}\right.$, geomagnetic disturbances index) with multiple sclerosis incidence in Tehran and western Greece, during the $23^{\text {rd }}$ solar cycle (1996-2008), by an ecological-correlational study. They found moderate to strong correlations among multiple sclerosis incidence of Tehran with $\mathrm{V}_{\mathrm{SW}}\left(\mathrm{r}_{\mathrm{S}}=0,665 ; \mathrm{p}=0,013\right)$, with 1 y delay, and also with $A_{P}$ $\left(r_{S}=0,864 ; p=0,001\right)$ with 2 y delay. There were very strong correlations among multiple sclerosis incidence data of Greece with $\mathrm{V}_{\mathrm{SW}}(\mathrm{r}=0,906 ; \mathrm{p}<0,001)$ and with $\mathrm{A}_{\mathrm{P}}(\mathrm{r}=0,844 ; \mathrm{p}=0.001)$, both with 1 y lag.

The aim of third study Sajedi and Abdollahi (2017) was to investigate which of insufficient received ultraviolet (UV) B radiation as mentioned risk factor for multiple sclerosis is correlated with long-term ultradecadal multiple sclerosis incidence. After a systematic search, long-term incidence reports of six locations were selected for this retrospective time-series study. Possible lead-lag relationships between multiple sclerosis incidence, geomagnetic disturbances andd UV were evaluated by cross-correlation analysis. Significant positive correlations between geomagnetic disturbances and multiple sclerosis incidence were seen in Tayside County (at lag of 2 ys: $r_{S}=0,38$ ), Denmark (peak correlation at lag of 2 ys: $r_{S}=0,53$ ), and UK (at lag of 1 y: $r_{S}=0,50$ ). Authors found a positive correlation between received UV and multiple sclerosis incidences in the Nordland at lag of $1 \mathrm{y}$ $\left(r_{S}=0,49\right)$. Authors concluded that this study found significant positive correlations between alterations in geomagnetic disturbances with alterations in long-term multiple sclerosis incidence in three out of six studied locations and supports the geomagnetic disturbances hypothesis. The observed significant correlation between multiple sclerosis and UV is positive; hence it is not supportive for UV related vitamin D deficiency hypothesis.

It follows from the above that the first examined contingent in our project should be patients with multiple sclerosis. And so it happened, but it happened purely by accident (how not to believe now in the will of providence!). By the way, the next contingents will be children with cerebral palsy, adults with arrhythmia and patients with chronic pyelonephritis, etc.

\section{Materials and methods}

Participants. The object of observation were 74 patients with multiple sclerosis and 14 patients with radiculopathies, who in the period from September 2014 to November 2018 conducted a one-time assessment of immune status by the relative content in the blood of lymphocytes of $\mathrm{CD}^{+}, \mathrm{CD} 4^{+}, \mathrm{CD}^{+}, \mathrm{CD} 25^{+}, \mathrm{CD}^{+} 6^{+}$and $\mathrm{CD} 19^{+}$phenotypes and serum level of Immunoglobulines $\mathrm{M}, \mathrm{G}, \mathrm{A}$ as well as CIC and IL-1 $\beta$.

Procedure / Test protocol / Skill test trial / Measure / Instruments. Phenotyping of blood lymphocytes was performed in the reaction of indirect immunofluorescence with antibodies labeled with fluorescein isothiocyanate (Pinchuk, Gluzman, 1990) using the appropriate monoclonal antibodies obtained from the RE Kavetsky Institute of Experimental Pathology, Radiology and Oncology National Academy of Sciences of Ukraine.

Evaluation of the indirect fluorescence reaction was performed using a luminescent microscope "LumamP8" with a phase contrast attachment. In serum was determined the content of circulating immune complexes (by precipitation with polyethylene glycol), Immunoglobulines G, A, M and Interleukine-1 $\beta$ (ELISA, analyzer "Stat Fax 303”, USA, reagents from “Vector-Best”, RF) (Lapovets', Lutsyk, 2004).

Retrospectively recorded the geomagnetic Ap-index (average value of variations of the Earth's magnetic field as a marker of geomagnetic activity) on the day of blood collection and during the previous 7 days, using a publicly available information resource http://wdc.kugi.kyoto-u.ac.jp/kp/index.html.

Data collection and analysis / Statistical analysis. Statistical processing was performed using a software package "Microsoft Excell" and "Statistica 12 StatSoft Inc".

\section{Results}

During the week, the average level of the Ar-index fluctuated within $12 \div 20 \mathrm{nT}$, resembling a sinusoid (Fig. 1). 


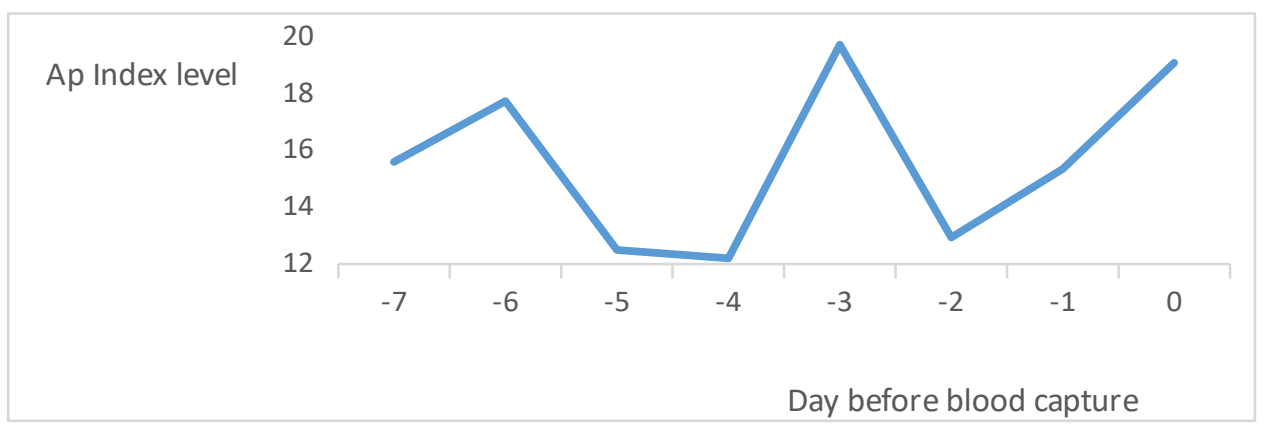

Fig. 1. Levels of Ap Geomagnetic index during 7 days before end on day blood capture

Initially, a matrix of correlation coefficients was created between the values of the Ap-index on the day of blood collection and for 7 days before it and the registered immune parameters (Table 1).

Table 1. Matrix of correlations between Ap Geomagnetic indices and Immune parameters

\begin{tabular}{|l|r|r|r|r|r|r|r|r|}
\hline & \multicolumn{9}{|c|}{} \\
\cline { 2 - 10 } & \multicolumn{10}{|c|}{ Ap7- } & Ap6- & Ap5- & Ap4- & Ap3- & Ap2- & Ap1- & Ap0 \\
\hline Variable & & & & & & & & \\
\hline Ap7- & 1,00 & 0,58 & 0,28 & 0,28 & 0,79 & 0,04 & 0,58 & 0,68 \\
\hline Ap6- & 0,58 & 1,00 & 0,70 & 0,45 & 0,50 & 0,05 & 0,52 & 0,50 \\
\hline Ap5- & 0,28 & 0,70 & 1,00 & 0,58 & 0,27 & 0,16 & 0,37 & 0,41 \\
\hline Ap4- & 0,28 & 0,45 & 0,58 & 1,00 & 0,30 & 0,08 & 0,21 & 0,23 \\
\hline Ap3- & 0,79 & 0,50 & 0,27 & 0,30 & 1,00 & 0,13 & 0,56 & 0,67 \\
\hline Ap2- & 0,04 & 0,05 & 0,16 & 0,08 & 0,13 & 1,00 & 0,56 & 0,38 \\
\hline Ap1- & 0,58 & 0,52 & 0,37 & 0,21 & 0,56 & 0,56 & 1,00 & 0,82 \\
\hline Ap0 & 0,68 & 0,50 & 0,41 & 0,23 & 0,67 & 0,38 & 0,82 & 1,00 \\
\hline CD4 & $-0,52$ & $-0,35$ & $-0,19$ & $-0,15$ & $-0,55$ & 0,05 & $-0,48$ & $-0,57$ \\
\hline CD8 & 0,15 & 0,14 & 0,04 & $-0,01$ & 0,19 & $-0,08$ & 0,10 & 0,13 \\
\hline CD19 & $-0,02$ & 0,03 & 0,15 & $-0,06$ & 0,09 & 0,17 & 0,21 & 0,12 \\
\hline CD56 & 0,57 & 0,34 & 0,14 & 0,15 & 0,54 & $-0,08$ & 0,43 & 0,56 \\
\hline CD25 & 0,31 & 0,22 & 0,17 & 0,17 & 0,45 & $-0,14$ & 0,25 & 0,35 \\
\hline IgA & 0,09 & 0,02 & 0,02 & $-0,00$ & $-0,02$ & $-0,01$ & 0,05 & 0,02 \\
\hline IgG & $-0,13$ & $-0,08$ & $-0,11$ & $-0,14$ & $-0,20$ & $-0,03$ & $-0,04$ & $-0,03$ \\
\hline IgM & $-0,10$ & $-0,10$ & $-0,09$ & 0,02 & $-0,07$ & $-0,04$ & $-0,05$ & $-0,17$ \\
\hline CIC & $-0,19$ & 0,06 & 0,11 & 0,13 & $-0,13$ & $-0,16$ & $-0,00$ & $-0,15$ \\
\hline IL-1 & $-0,17$ & $-0,11$ & 0,15 & 0,04 & $-0,09$ & 0,31 & 0,06 & 0,21 \\
\hline
\end{tabular}

Noteworthy connections are visualized in Fig. 2.

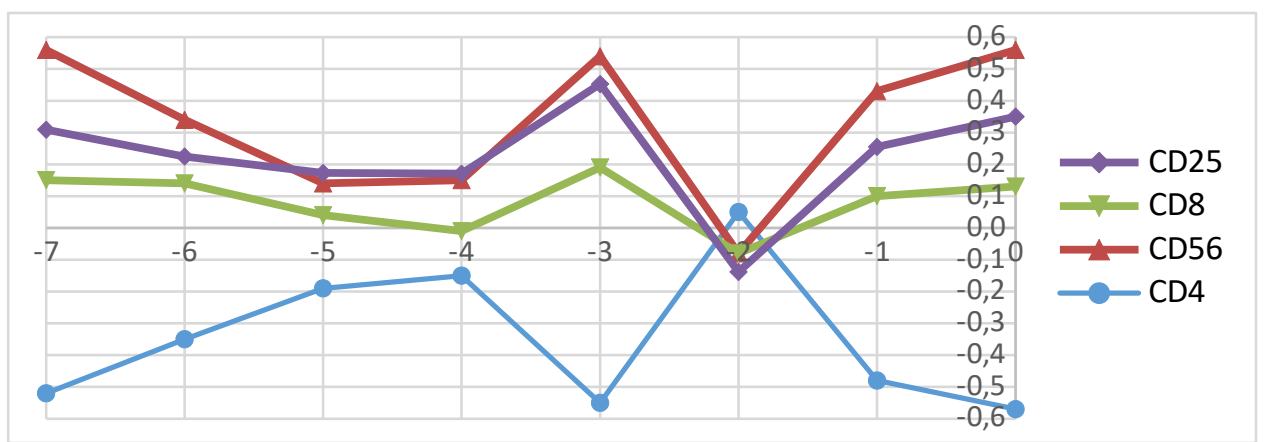

Fig. 2. Correlation coefficients between Ap-index during 7 days before and on day blood capture and lymphocytes populations levels

As we can see, the strongest geomagnetic-immune relationships take place on the day of blood sampling 
for analysis, as well as three and seven days before it, ie on the days of the peaks of the Ap-index (with a lag relative to the seventh day).

The obvious mirroring of the patterns of correlation coefficients of natural killers and T-helpers is due to their strong inverse correlation (Fig. 3).

Figures 4 and 5 show the opposite in nature and close in strength correlations of the Ap-index on the day of blood collection with the relative content of natural killers and T-helpers.

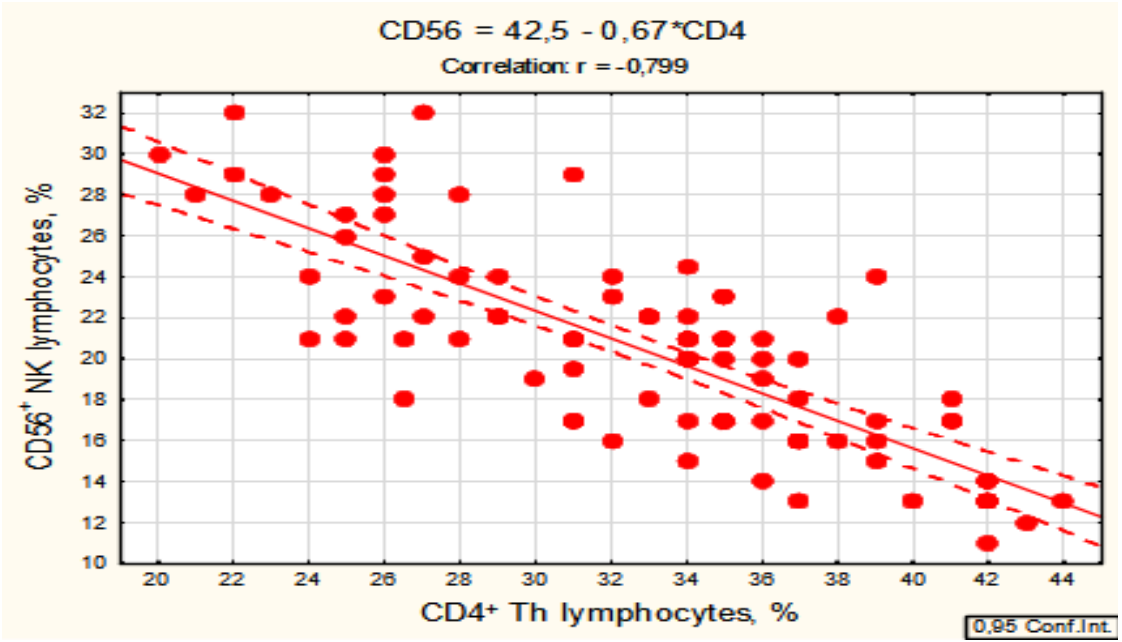

Fig. 3. Scatterplot of correlation between $\mathrm{CD4}^{+}\left(\mathrm{X}\right.$-line) and $\mathrm{CD56}^{+}$(Y-line) lymphocytes level

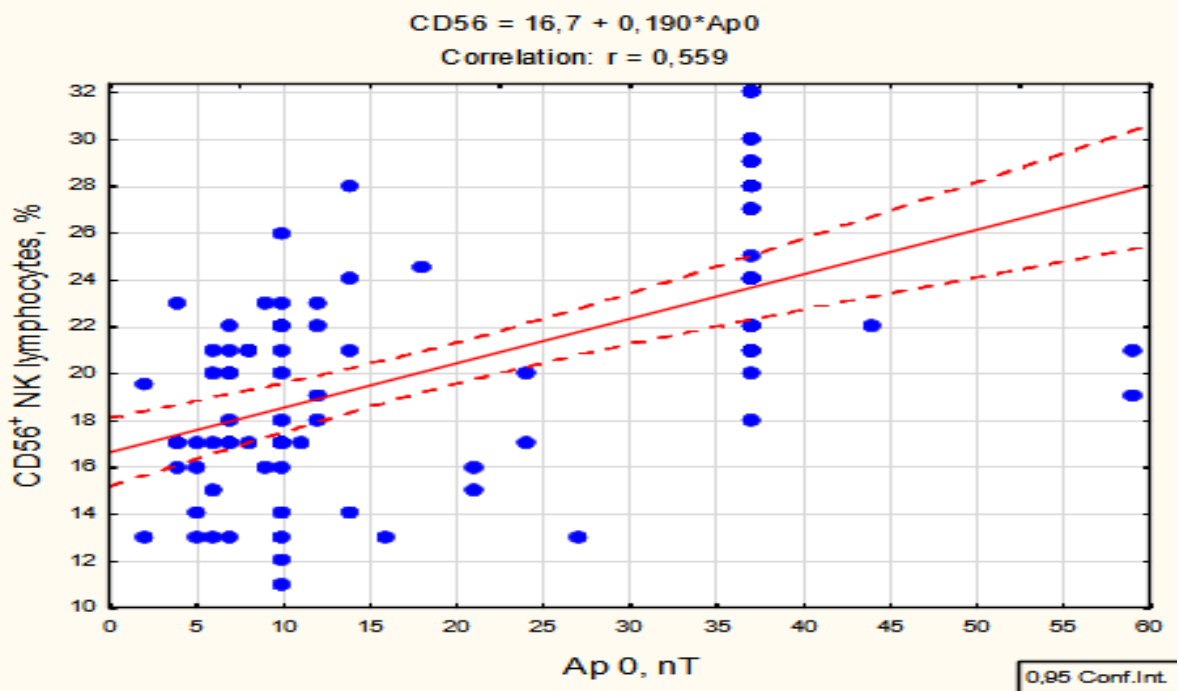

Fig. 4. Scatterplot of correlation between Ap-index on day blood capture (X-line) and $\mathrm{CDS6}^{+} \mathrm{NK}^{\mathrm{N}}$ lymphocytes level 


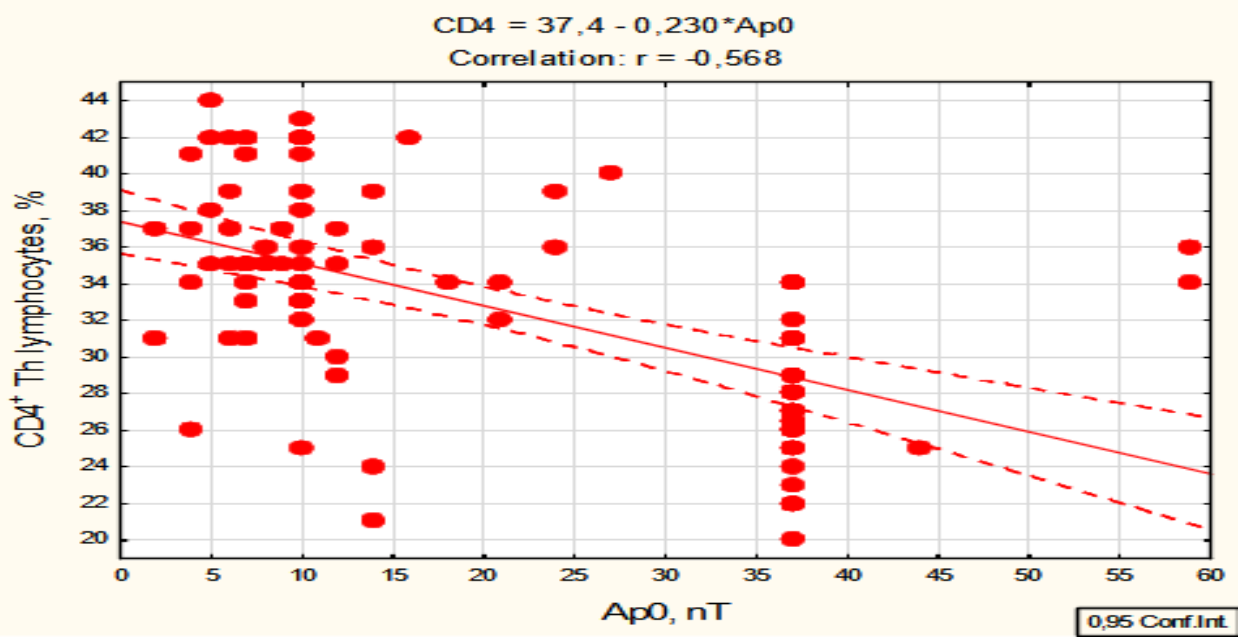

Fig. 5. Scatterplot of correlation between Ap-index on day blood capture (X-line) and $\mathrm{CD}^{+}{ }^{+} \mathrm{Th}$ lymphocytes level

The regression model with step-by-step exclusion also included correlation coefficients 1, 3, 6 and 7 days before blood collection. As a result, it was stated that the Ap-index determines the level of natural killers by $38,7 \%$ (Fig. 6), and T-helpers by $38,0 \%$ (Fig. 7).

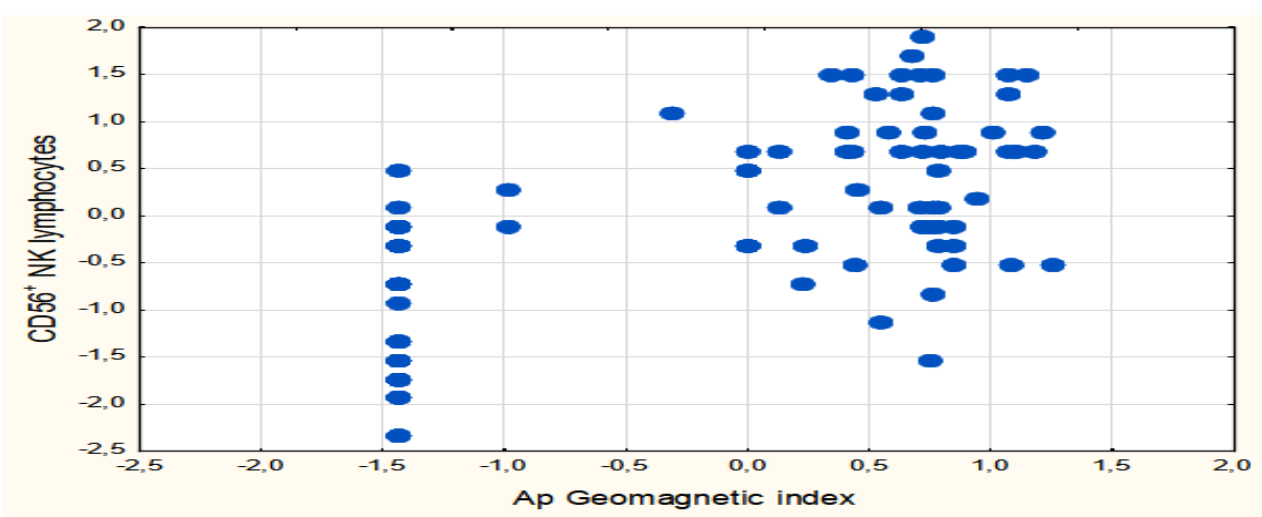

$\mathrm{R}=0,622 ; \mathrm{R}^{2}=0,387 ; \chi_{(5)}^{2}=41 ; \mathrm{p}<10^{-6} ; \Lambda$ Prime $=0,613$

Fig. 6. Scatterplot of canonical correlation between Ap-indices before 7, 6, 3, 1 days and on day blood capture (X-line) and $\mathrm{CD56}^{+} \mathrm{NK}$ lymphocytes level

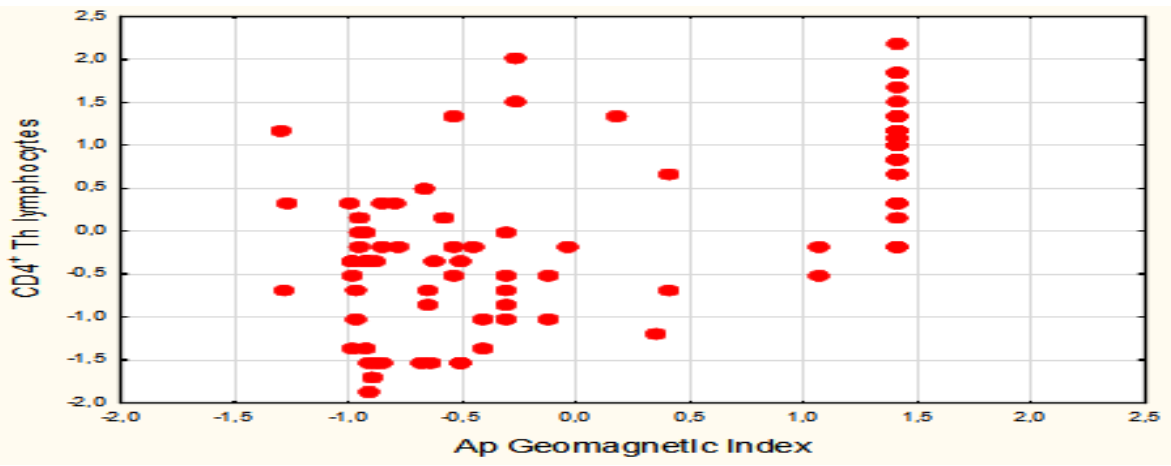

$\mathrm{R}=0,617 ; \mathrm{R}^{2}=0,380 ; \chi_{(5)}^{2}=40 ; \mathrm{p}<10^{-6} ; \Lambda$ Prime $=0,620$

Fig. 7. Scatterplot of canonical correlation between Ap-indices before 7, 6, 3, 1 days and on day blood capture (X-line) and $\mathrm{CD}^{+}{ }^{+} \mathrm{Th}$ lymphocytes level

Also positively, but much weaker, correlates the A-index with the level of $\mathrm{CD} 25^{+}$T-lymphocytes (Fig. 1), determining them by $22,6 \%$ (Fig. 8 ). 


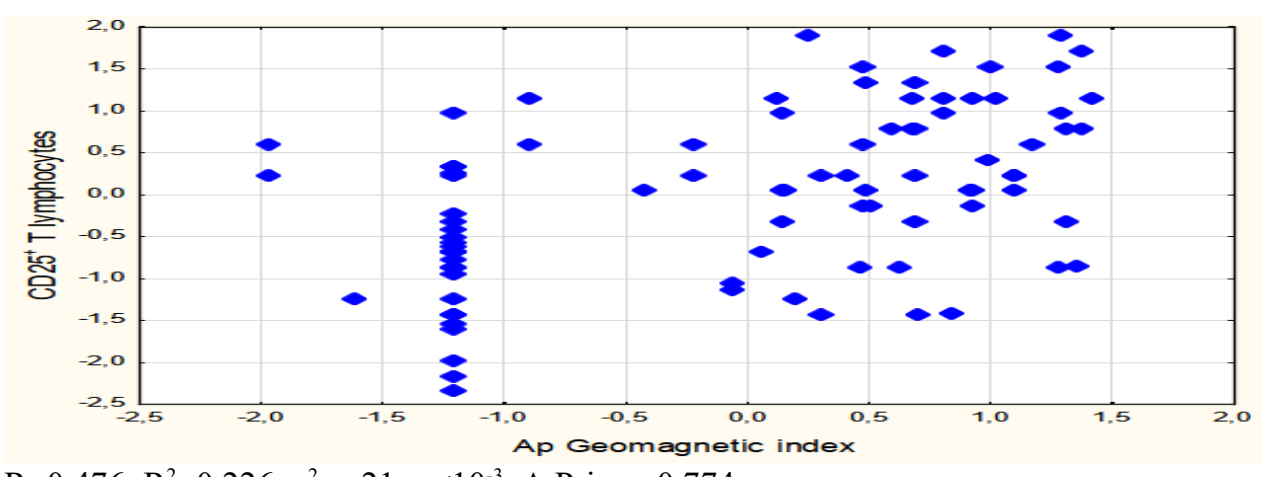

$\mathrm{R}=0,476 ; \mathrm{R}^{2}=0,226 ; \chi^{2}{ }_{(5)}=21 ; \mathrm{p}<10^{-3} ; \Lambda$ Prime $=0,774$

Fig. 8. Scatterplot of canonical correlation between Ap-indices before 7, 6, 3, 1 days and on day blood capture (X-line) and $\mathrm{CD}^{+} \mathrm{T}$ lymphocytes level

In contrast, the level of IL-1 $\beta$ Ap-index significantly correlates only on the day of blood collection and 2 days before it (Fig. 1), determining it by 24,1\% (Fig. 9).

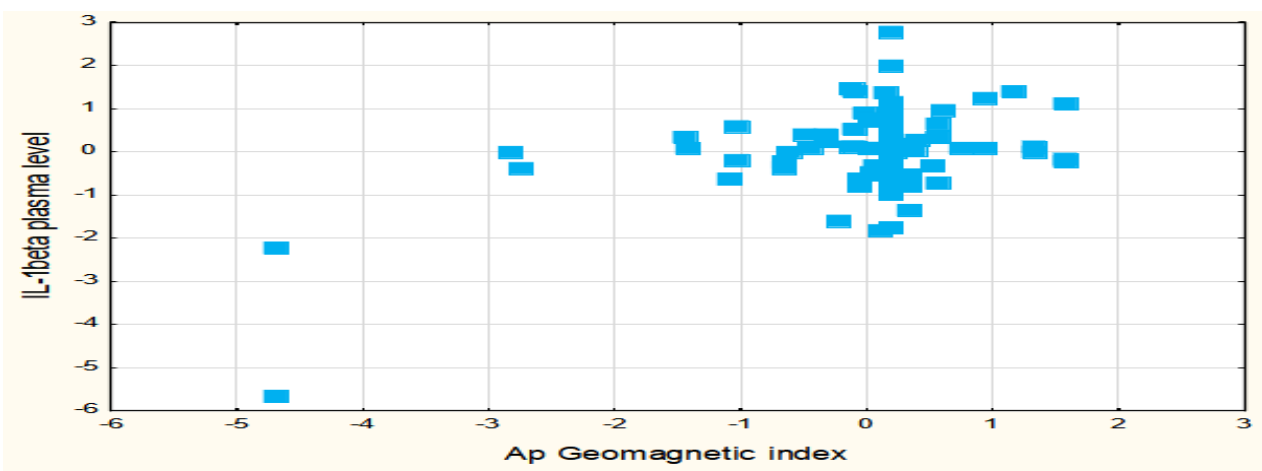

$\mathrm{R}=0,491 ; \mathrm{R}^{2}=0,241 ; \chi^{2}{ }_{(4)}=23 ; \mathrm{p}<10^{-4} ; \Lambda$ Prime $=0,759$

Fig. 9. Scatterplot of canonical correlation between Ap-indices before 7, 5, 2 days and on day blood capture (X-line) and IL-1ß plasma level

In the analysis of the canonical correlation between the levels of Ap-indices, on the one hand, and immunity parameters - on the other hand, T-killers and IgM were included in the model, despite insignificant values of coefficients, while outside the model turned out B-lymphocytes, Igg G and A and CIC, as well as Apindex 4 days before blood sampling (Table 2).

Table 2. Matrix of correlations between Ap Geomagnetic indices and Immune parameters included in canonical model

\begin{tabular}{|l|c|c|c|c|c|r|}
\hline \multirow{2}{*}{$\begin{array}{l}\text { Root } \\
\text { Variable }\end{array}$} & \multicolumn{6}{|c|}{ Correlations, left set with right set } \\
\cline { 2 - 7 } & CD4 & CD8 & CD56 & CD25 & IgM & IL-1 \\
\hline Ap7- & $-0,521$ & 0,149 & 0,567 & 0,309 & $-0,103$ & $-0,169$ \\
\hline Ap6- & $-0,347$ & 0,137 & 0,338 & 0,225 & $-0,099$ & $-0,106$ \\
\hline Ap5- & $-0,192$ & 0,038 & 0,138 & 0,173 & $-0,086$ & 0,149 \\
\hline Ap3- & $-0,553$ & 0,190 & 0,536 & 0,453 & $-0,072$ & $-0,091$ \\
\hline Ap2- & 0,049 & $-0,079$ & $-0,075$ & $-0,138$ & $-0,036$ & 0,307 \\
\hline Ap1- & $-0,482$ & 0,099 & 0,430 & 0,255 & $-0,055$ & 0,061 \\
\hline Ap0 & $-0,568$ & 0,127 & 0,559 & 0,350 & $-0,167$ & 0,206 \\
\hline
\end{tabular}

Judging by the factor loads on the geomagnetic canonical root (Table 3), the maximum immunomodulatory effect is caused by the perturbation of the Earth's magnetic field on the day of blood collection, and slightly weaker - 1, 3 and 7 days before collection. And according to the factor loads on the immune canonical root, the most sensitive to geomagnetic disturbances are downregulated T-helpers and upregulated natural killers and activated T-lymphocytes. Significantly less subject to enhancing effects of terrestrial magnetism levels of T-killers and IL-1 $\beta$ and suppressor effects - IgM. 
Table 3. Factor Structure for Geomagnetic and Immune Canonical Roots

\begin{tabular}{|c|c|c|c|}
\hline \multirow{3}{*}{ Variable } & \multirow{2}{*}{ Factor Structure, left set } & \multirow[b]{2}{*}{ Variable } & Factor Structure, right set \\
\hline & & & Root 1 \\
\hline & Root 1 & CD4 & $-0,825$ \\
\hline Ap7- & 0,590 & $\mathrm{CD} 8$ & 0,222 \\
\hline Ap6- & 0,405 & CD56 & 0.792 \\
\hline Ap5- & 0,362 & \begin{tabular}{|l|l}
$\operatorname{Con} 25$ \\
$\cos 25$
\end{tabular} & $\frac{0,192}{0,633}$ \\
\hline Ap3- & 0,718 & CDL5 & 0,633 \\
\hline Ap2- & 0,093 & $\lg \mathrm{M}$ & $-0,214$ \\
\hline Ap1- & 0,617 & IL-1 & 0,256 \\
\hline $\mathrm{Ap0}$ & 0,915 & & \\
\hline
\end{tabular}

In general, the perturbation of the Earth's magnetic field determines the registered immune parameters by $54,9 \%$ (Fig. 10).

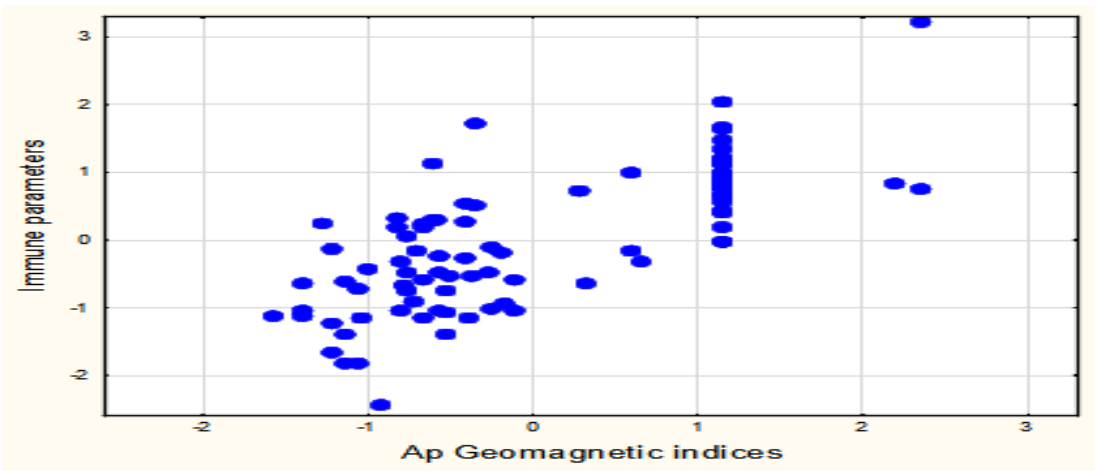

$\mathrm{R}=0,741 ; \mathrm{R}^{2}=0,549 ; \chi_{(42)}^{2}=130 ; \mathrm{p}<10^{-6} ; \Lambda$ Prime $=0,180$

Fig. 10. Scatterplot of canonical correlation between Ap Geomagnetic indices before 7 days and on day blood capture (X-line) and Immune parameters (Y-line)

\section{Discussion}

First of all, note that multiple sclerosis is not specifically sensitive to geomagnetic disturbances.

Wing et al (2015) for examine the influence of solar cycle and geomagnetic effects on the incidence of autoimmune diseases giant cell arteritis and rheumatoid arthritis used data from patients obtained from population-based cohorts. Yearly trends in age-adjusted and sex-adjusted incidence were correlated with the $F_{10.7}$ index (solar radiation at $10.7 \mathrm{~cm}$ wavelength, a proxy for the solar extreme ultraviolet radiation) and AL index (a proxy for the westward auroral electrojet and a measure of geomagnetic activity). Fourier analysis was performed on $\mathrm{AL}, \mathrm{F}_{10.7}$, and giant cell arteritis and rheumatoid arthritis incidence rates. The correlation of giant cell arteritis incidence with AL is highly significant: giant cell arteritis incidence peaks $0-1$ year after the AL reaches its minimum (ie, auroral electrojet reaches a maximum). The correlation of rheumatoid arthritis incidence with AL is also highly significant. rheumatoid arthritis incidence rates are lowest 5-7 years after AL reaches maximum. AL, giant cell arteritis and rheumatoid arthritis incidence power spectra are similar: they have a main peak (periodicity) at about 10 years and a minor peak at $4-5$ years. However, the rheumatoid arthritis incidence power spectrum main peak is broader (8-11 years), which partly explains the lower correlation between rheumatoid arthritis onset and AL. The auroral electrojets may be linked to the decline of rheumatoid arthritis incidence more strongly than the onset of rheumatoid arthritis. The incidences of rheumatoid arthritis and giant cell arteritis are aligned in geomagnetic latitude. Thus, AL and the incidences of giant cell arteritis and rheumatoid arthritis all have a major periodicity of about 10 years and a secondary periodicity at 4-5 years. Geomagnetic activity may explain the temporal and spatial variations, including east-west skewness in geographic coordinates, in giant cell arteritis and rheumatoid arthritis incidence, although the mechanism is unknown. The link with solar, geospace and atmospheric parameters need to be investigated. Authors concluded that these novel findings warrant examination in other populations and with other autoimmune diseases.

One of the processes that can increase the magnetic activity and disturb the Earth's magnetic and electric fields is the substorm, in which magnetic energy stored in the magnetosphere is released and energises electrons and ions (Consolini et al, 2005). Substorms occur most frequently in the declining phase of the solar cycle, when the occurrence of the solar wind high-speed stream interfaces is also maximal (Pulkkinen et al, 2011; Kissinger et al, 2011). Substorm activities can increase the auroral electrojets, particularly the westward electrojet 
(Pulkkinen et al, 2011). Auroral electrojets are currents that flow in the ionosphere within the auroral oval, a ring-like structure that hovers a few hundred kilometres above the northern and southern polar regions. The AL index, which is derived from magnetic field perturbations at high latitudes, provides a measure of the strength of the westward auroral electrojet (Davis, Sugiura, 1966). Lower AL value indicates higher geomagnetic activity and stronger auroral electrojet current.

Although the mechanism for this geomagnetic effect has not been established, one possibility is that geomagnetic disturbances result in reduced melatonin excretion (Palmer et al, 2006). Burch et al (1999) found that on days when the geomagnetic activity was high, the mean excretion of the overnight melatonin metabolite (6-OHMS) was approximately $21 \%$ lower than on days when geomagnetic activity was low, in a study of 142 male electric power workers who were exposed to ambient light and a magnetic field generated from $60 \mathrm{~Hz}$ electric power. Melatonin has been shown to act as an anti-inflammatory agent and generally has an immuneenhancing effect in many species, including humans, by providing a circadian immunoregulatory signal to the immune system (Esquifino et al, 2004; Cuzzocrea, Reiter, 2001; Ha et al, 2005). Melatonin scavenges and inactivates oxygen-derived free radicals (reactive chemical species with unpaired electrons in their outer orbitals), such as, $\mathrm{ONOO}^{-}$, and $\mathrm{OH}$, all of which have been found at the site of inflammation (Cuzzocrea, Reiter, 2001). Remans et al (2005) also reported the association of free radicals and RA. Esquifino et al (2004) found that daily injections of melatonin restored the inflammatory response in old rats to the level found in young rats. Further mechanistic studies of the effects of geomagnetic activity are needed.

Many authors noticed correlation between dynamics of immunological parameters in healthy people and Solar cycles: in years of maximum solar activity average leukocyte count decreased 1,5-1,67-times that in low solar activity phase and blood formula shifted towards lymphocytosis (Breus et al, 2002).

Bonhomme-Faivre et al (2003) examined immunological disorders in 6 individuals who had been exposed occupationally to environmental electromagnetic fields. Comparable effects on mice exposed in a similar environment were also investigated. The human subjects had worked $8 \mathrm{hr} /$ day for $5 \mathrm{yr}$ in a laboratory located above electrical transformers and high-tension cables, and in which there were low-frequency electromagnetic fields of $0,2-6,6 \mu \mathrm{T}$, ten times weaker than the geomagnetic field strength $(35-65 \mu \mathrm{T})$. The 6 control subjects (matched for socioeconomic parameters, sex, and age) had worked away from the immediate vicinity of transformers and high-tension cables. The authors found statistically significantly lower total lymphocyte, CD4, and CD3 counts, and significantly increased natural killer (NK) cells, in exposed subjects vs controls. Six months after exposure had ceased, total lymphocyte counts had increased, as had CD4, CD3, and CD19 counts $(+13 \%,+28 \%,+22 \%$, and $+17 \%$, respectively), and NK cell counts were decreased by $26 \%$ (not significant) in the same human subjects. In the second part of this study, 12 Swiss male mice housed in cages were exposed in the same room in which the human subjects had been exposed (i.e., $5 \mu \mathrm{T}, 50-\mathrm{Hz}$ magnetic field) for 109 days; 12 additional mice were used as unexposed controls. The total lymphocyte, leukocyte, polymorphonuclear neutrophil, CD4, and NK counts of the exposed mice at 109 days were significantly lower than those of controls. In addition, plasma glucose levels (at 30 days) and amylase activity (at 109 days) were significantly lower, whereas plasma sodium and chloride levels were significantly elevated at 109 days. Results from this study suggest that chronic exposure to a 0,2-6,6 $\mu \mathrm{T}$ magnetic field can lead to decreased immunological parameters (total lymphocytes and CD4 counts) in both humans and mice. The increase in some values once exposure was terminated suggests a causal relationship with exposure to electromagnetic fields, as do the changes in mice, particularly the changes in total lymphocyte and CD4 counts.

Frahm et al (2006) demonstrate the capacity of extremely low frequency electromagnetic fields (ELFEMF) to stimulate physiological cell functions in mouse macrophages shown by the significantly elevated phagocytic activity, free radical release, and IL-1及 production suggesting the cell activation capacity of ELFEMF in the absence of any genotoxic effects. In this study, the influence of $50 \mathrm{~Hz}$ magnetic fields (MF) at 1,0 $\mathrm{mT}$ was investigated on the phagocytic activity and on the IL-1 $\beta$ production in differentiated macrophages. MFexposure led to an increased phagocytic activity after $45 \mathrm{~min}$, shown as a 1,6-fold increased uptake of latex beads in MF-exposed cells compared to controls. Authors also demonstrate an increased IL- $1 \beta$ release in macrophages after $24 \mathrm{~h}$ exposure (1,0 mT MF). Time-dependent IL-1 $\beta$ formation was significantly increased already after $4 \mathrm{~h}$ and reached a maximum of 12,3-fold increase after $24 \mathrm{~h}$ compared to controls. Obtained data show no significant differences in micronucleus formation or irregular mitotic activities in exposed cells. Furthermore, the effects of different flux densities (ranging from 0,05 up to 1,0 $\mathrm{mT}$ for $45 \mathrm{~min}$ ) of $50 \mathrm{~Hz} \mathrm{MF}$ was tested on free radical formation as an endpoint of cell activation in mouse macrophage precursor cells. All tested flux densities significantly stimulated the formation of free radicals.

Other study of these authors (Lupke et al, 2006) focused on the cell activating capacity of extremely low frequency magnetic fields on human umbilical cord blood-derived monocytes. Obtained results confirm the previous findings of cell activating capacity of ELF-MF $(1,0 \mathrm{mT})$ in human monocytes, which was detected as an increased ROS release. Furthermore, gene expression profiling was performed to achieve a comprehensive view of involved genes during the cell activation process after 45 min ELF-MF exposure. Results indicate the alteration of 986 genes involved in metabolism, cellular physiological processes, signal transduction and 
immune response. Real-time RT-PCR analysis of the kinetic of the expression of IL-15 and IL-10 receptors (alpha chain) during 45 min ELF-MF exposure indicates the regulation of cell activation via the alternative pathway, whereas the delayed gene expression of FOS, IL-2RA and the melatonin synthesizing enzyme HIOMT suggests the suppression of inflammatory processes.

Thus, studies demonstrate distinct changes in gene expression in cells exposed to a weak magnetic field (MF). Mechanisms of this phenomenon are not understood yet.

It was proposed that membrane-mediated $\mathrm{Ca}^{2+}$ signaling processes are involved in the mediation of the electromagnetic field effects on the immune system (Walleczek, 1992). Application of low frequency electromagnetic fields produce parallel shifts in $\mathrm{Ca}^{2+}$ uptake and DNA replication intensity in stimulated lymphocytes (Conti et al, 1985). Exposure of immune cells to static magnetic field resulted in decrease of phagocytic activity, inhibition of mitogenic response to Con A in lymphocytes and enhancement of apoptosis in thymic cells (Flipo et al, 1998). Together, the data demonstrate the possibility of $\mathrm{Ca}^{2+}$ signaling-mediated immunomodulating effects of exposure to magnetic fields. Thus, calcium signaling and $\mathrm{Ca}^{2+}$-dependent transcriptional network represents another possible target of electromagnetic field influence on biological functions and host-pathogen interactions.

Zaporozhan and Ponomarenko (2010) propose that proteins of the Cryptochrome family (CRY) are "epigenetic sensors" of the magnetic field fluctuations, i.e., magnetic field-sensitive part of the epigenetic controlling mechanism. It was shown that CRY represses activity of the major circadian transcriptional complex CLOCK/BMAL1. At the same time, function of CRY, is apparently highly responsive to weak magnetic field because of radical pairs that periodically arise in the functionally active site of CRY and mediate the radical pair mechanism of magnetoreception. It is known that the circadian complex influences function of every organ and tissue, including modulation of both NF- $\mathrm{BB}$ - and glucocorticoids-dependent signaling pathways. Thus, magnetic fields and solar cycles-dependent geomagnetic field fluctuations are capable of altering expression of genes related to function of $\mathrm{NF}-\kappa \mathrm{B}$, hormones and other biological regulators. Notably, NF- $\mathrm{B}$, along with its significant role in immune response, also participates in differential regulation of influenza virus RNA synthesis. Presented data suggests that in the case of global application (example - geomagnetic field), magnetic fieldmediated regulation may have epidemiological and other consequences.

The earth's magnetic field is also highly dependent upon solar activity, including changes due to solar storms and sunspot indices. Changes in solar radiation directly affect Earth's magnetic field, with effects that can be strong enough to disrupt communications and power distribution networks. Solar-induced fluctuations in the ambient geomagnetic field have been correlated with a wide range of biological effects (Muehsam and Ventura, 2014), including changes in ultrastructure of cardiomyocytes, temporal changes in blood pressure (Breus et al, $2002)$, changes in power in the gamma $(>30 \mathrm{~Hz})$ and theta $(4-8 \mathrm{~Hz})$ brain wave frequencies in humans (Babayev and Allahverdiyeva, 2007; Mulligan et al, 2010), coherence of human EEG oscillations (Novik and Smirnov, 2013). Importantly, changes in solar/geomagnetic activity have also been shown to impact human health in a clinically-relevant manner. Increased solar activity has been correlated with a substantially increased rate of myocardial infarctions (Halberg et al, 2000; Vencloviene et al, 2013), decreased survival of acute coronary syndromes (Vencloviene et al, 2014), higher mortality from acute myocardial infarction, higher diastolic arterial pressure in healthy subjects and in treated hypertensive patients, higher prolactin and 17-corticosteroid levels in the peripheral blood, more severe migraine attacks and more admissions for cerebrovascular accident and cerebrovascular insufficiency in male patients, changes in many blood coagulation cellular gradients (platelet count, basophils in the peripheral blood), a rise in platelet aggregation, fibrinogen level and a drop in leukocyte adhesiveness (Stoupel, 2002), increased mortality due to a wide range of factors (Stoupel et al, 2002), decreased human lifespan (Lowell, Davis, Jr, 2008), and increased rate of clinical admissions for convulsive seizures (Rajaram and Mitra, 1981). These results show that in addition to diurnal and seasonal solar rhythms, biological coupling with transient solar storm activity and the 11-year solar cycle also occurs, with clinically and socially significant effects.

Baevsky et al (1997) examined how heart rate variability (HRV) relates to the risk of ischemic heart disease (IHD) and may provide a means to assess effects of exposure to geomagnetic storms. In Stockholm, the 24-hour SD of hourly estimates of heart rate (HR) were obtained by Holter monitoring from 50 men who had had an acute myocardial infarction or had angina pectoris and compared to that of 50 clinically healthy men of similar age. In Tokyo, the HR 121 normotensives and 176 treated hypertensives was monitored. The incidence of IHD was recorded prospectively for 6 years. These results are aligned with those of a retrospective analysis of archived data on all crews of the Soyuz spacecraft for 1990-1994 focused on ECG from cosmonauts (47 males and 2 females) at times corresponding to geomagnetic storms. The results clearly indicate a decrease in HRV in association with IHD (20.5\%, p=0.002 in Stockholm, 20.0\%, p=0.04 in Tokyo). By comparison, the about 30\% decrease $(\mathrm{p}=0.041)$ in RMSSD of HR in cosmonauts studied during a geomagnetic storm as compared to cosmonauts monitored on quiet days adds supportive evidence to the proposition that exposure to geomagnetic disturbances increases cardiovascular disease risk. 
These data suggest that geomagnetic immunomodulation can be realized not only through direct effects on immunocytes, but also through the mediation of the autonomic and central nervous systems. The reality of such a mechanism is evidenced by well-known data on neuro-immune relationships (Nance and Sanders, 2007; Tracey, 2007; Thayer and Sternberg, 2010; Popovych et al., 2020). In particular, according to the Truskavetsian Scientific School, the parameters of EEG and HRV are interrelated (Popovych et al, 2013; 2014) and have a stimulating effect on the level of T-helpers in the blood and a suppressive effect on the level of natural and Tkillers (Kulchyns'kyi et al, 2016; 2017; 2017a; 2017b; Popovych et al, 2017; 2018).

\section{Compliance with Ethical Standards}

Conflict of Interest The authors declare that they have no conflict of interest.

Ethical Approval All procedures performed in studies involving human participants were in accordance with the ethical standards of the institutional and/or national research committee and with the 1964 Helsinki declaration and its later amendments or comparable ethical standards.

Informed Consent Informed Consent Informed consent was obtained from all individual participants included in the study. All subjects of the institutional survey gave consent for anonymized data to be used for publication purposes.

\section{References}

Abdollahi, F., Sajedi, S. (2014). Correlation of multiple sclerosis (MS) incidence trends with solar and geomagnetic indices: Time to revise the method of reporting MS epidemiological data. Iran J Neurol, 13(2), 64-69.

Babayev, E., Allahverdiyeva, A. (2007). Effects of geomagnetic activity variations on the physiological and psychological state of functionally healthy humans: some of results of the Azerbijani studies. Advances in Space Research, 40, 1941-1951.

Baevsky, R., Petrov, V., Cornelissen, G., Halberg, F., Orth-Gomer, K., Akerstedt, T., Otsuka, K., Breus, T., Siegelova, J., Dusek, J., Fiser, B. (1997). Meta-analyzed heart rate variability, exposure to geomagnetic storms, and the risk of ischemic heart disease. Scr Med (Brno), 70(4-5), 201-206.

Bonhomme-Faivre, L., Marion, S., Forestier, F., Santini, R., Auclair, H. (2003). Effects of electromagnetic fields on the immune systems of occupationally exposed humans and mice. Arch Environ Health, 58(11), 712-717. doi: 10.3200/AEOH.58.11.712-717.

Breus, T., Ozheredov, V., Syutkina, E., Rogoza, A. (2008). Some aspects of the biological effects of space weather. J Atmos Sol-Terr Phy, 70(2-4), 436-441.

Breus, T., Pimenov, K., Cornélissen, G., Halberg, E., Syutkina, E., Baevsky, R., Petrov, V., Orth-Gómer, K., Akerstedt, T., Otsuka, K., Watanabe, Y., Chibisov, S. (2002). The biological effects of solar activity. Biomed Pharmacother, 56 (Suppl 2), 273-283.

Burch, J., Reif, J., Yost, M. (1999). Geomagnetic disturbances are associated with reduced nocturnal excretion of a melatonin metabolite in humans. Neurosci Lett, 266, 209-12. doi: 10.1016/S0304-3940(99)00308-0.

Chizhevsky, A. (1976). The Terrestrial Echo of Solar Storms (in Russian). Moscow. Mysl; 366 p.

Chizhevsky, A. (1995). The Cosmic Pulse of Life. The Earth is Embraced by the Sun. Heliotaraxia (in Russian). Moscow. Mysl; 766 p.

Christiansen,,C., Christensen, S., Farkas, D., Mire,t M., Sorensen, H., Pedersen, L. (2010). Risk of arterial cardiovascular diseases in patients with multiple sclerosis: a population-based cohort study. Neuroepidemiology. 35(4), 267-274. doi: 10.1159/000320245.

Cocek, A., Hahn, A., Ambrus, M., Dohnalova, A., Jandova, A., Pokorny, J. (2008). Changes of leukocyte adherence ability under the influence of magnetic field in the course of a treatment of patients with laryngeal and pharyngeal carcinoma. Electromagn Biol Med, 27(3), 277-288. doi: $10.1080 / 15368370802277724$.

Consolini, G., Kretzschmar, M., Lui, A. et al. (2005). On the magnetic field fluctuations during magnetospheric tail current disruption: a statistical approach. J Geophys Res Space Phys, 110, A07202. doi: 10.1029/2004JA010947.

Conti, P., Gigante, G., Alesse, E., Cifone, M., Fieschi, C., Reale, M., Angeletti, P. (1985). A role for Ca ${ }^{2+}$ in the effect of very low frequency electromagnetic field on the blastogenesis of human lymphocytes. FEBS Lett, 181, 28-32.

Cuzzocrea, S., Reiter, R.. (2001). Pharmacological action of melatonin in shock, inflammation and ischemia / reperfusion injury. Eur J Pharmacol, 426, 1-10. doi: 10.1016/S0014-2999(01) 01175-X.

Davis, T., Sugiura, M. (1966). Auroral electrojet activity index AE and its universal time variations. J Geophys Res, 71, 785-801. doi: 10.1029/JZ071i003p00785.

Dubrov, A. (2013). The Geomagnetic Field and Life: Geomagnetobiology. Springer.

Esquifino, A., Pandi-Perumal, S., Cardinali, D. (2004). Circadian organization of the immune response: a role for melatonin. Clin Appl Immunol Rev, 4, 423-33. doi: 10.1016/j.cair.2004.08.002. 
Flipo, D., Fournier, M., Benquet, C., Roux, P., Le Boulaire, C., Pinsky, C., LaBella, F., Krzystyniak, K. (1998). Increased apoptosis, changes in intracellular $\mathrm{Ca}^{2+}$, and functional alterations in lymphocytes and macrophages after in vitro exposure to static magnetic field. J Toxicol Environ Health A, 54, 63-76.

Frahm, J., Lantow, M., Lupke, M., Weiss, D., Simkó, M. (2006). Alteration in cellular functions in mouse macrophages after exposure to $50 \mathrm{~Hz}$ magnetic fields. J Cell Biochem, 99(1), 168-177. doi: $10.1002 /$ jcb.20920.

Gozhenko, A., Biryukov, V., Gozhenko, O., Zukow, W. (2018a). Health as a space-time continuum. Journal of Education, Health and Sport, 8(11), 763-777. doi: http://dx.doi.org/10.5281/zenodo.2657000.

Gozhenko, A., Biryukov, V., Muszkieta, R., Zukow, W. (2018b). Physiological basis of human longevity: the concept of a cascade of human aging mechanism. Collegium antropologicum, 42(2), 139-146.

Ha, E., Choe, B., Jung, K. et al. (2005). Positive relationship between melatonin receptor type 1B polymorphism and rheumatoid factor in rheumatoid arthritis patients in the Korean population. J Pineal Res, 39, 201205. doi: 10.1111/j.1600-079X. 2005.00237.x.

Halberg, F., Cornélissen, G., Otsuka, K., Watanabe, Y. et al. (2000). Cross-spectrally coherent 10.5- and 21year biological and physical cycles, magnetic storms and myocardial infarctions. Neuro Endocrinol Lett, 21(3), 233-258.

Hanslmeier, A. (2007). The Sun and Space Weather. 2. Dordrecht: Springer.

Jandova, A,, Mhamdi, L, Nedbalova, M, Cocek, A, Trojan, S, Dohnalova, A, Pokorny, J. (2005). Effects of Magnetic Field 0.1 and $0.05 \mathrm{mT}$ on Leukocyte Adherence Inhibition.Electromagn Biol Med, 24(3), 283-292. doi: 10.1080/15368370500379681.

Kirschvink, J., Kobayashi-Kirschvink, A., Woodford, B. (1992). Magnetite biomineralization in the human brain. Proc Natl Acad Sci USA, 89(16), 7683-7687. doi: 10.1073 /pnas.89. 16. 7683.

Kirschvink, J., Kobayashi-Kirschvink, A., Diaz-Ricci, J., Kirschvink, S. (1992). Magnetite in human tissues: a mechanism for the biological effects of weak ELF magnetic fields. Bioelectromagnetics, (Suppl 1), $101-113$.

Kissinger, J., McPherron, R., Hsu, T. et al. (2011). Steady magnetospheric convection and stream interfaces: relationship over a solar cycle. J Geophys Res Space Phys, 116, A00I19. doi: 10.1029/2010JA015763.

Kul'chyns'kyi, A., Gozhenko, A., Zukow, W., Popovych, I. (2017). Neuro-immune relationships at patients with chronic pyelonephrite and cholecystite. Communication 3. Correlations between parameters EEG, HRV and Immunogram. Journal of Education, Health and Sport, 7(3), 53-71.

Kul'chyns'kyi, A., Kovbasnyuk, M., Kyjenko, V., Zukow, W., Popovych, I. (2016). Neuro-immune relationships at patients with chronic pyelonephrite and cholecystite. Communication 2. Correlations between parameters EEG, HRV and Phagocytosis. Journal of Education, Health and Sport, 6(10), 377401.

Kul'chyns'kyi, A., Kyjenko, V., Zukow, W., Popovych, I. (2017). Causal neuro-immune relationships at patients with chronic pyelonephritis and cholecystitis. Correlations between parameters EEG, HRV and white blood cell count. Open Medicine, 12(1), 201-213.

Kul'chyns'kyi, A., Zukow, W., Korolyshyn, T., Popovych, I. (2017). Interrelations between changes in parameters of HRV, EEG and humoral immunity at patients with chronic pyelonephritis and cholecystitis. Journal of Education, Health and Sport, 7(9), 439-459.

Lapovets', L., Lutsyk, B. (2004). Laboratory Immunology (in Ukrainian). Kyiv, 173 p.

Lebel, R., Eissa, A., Seres, P., Blevins, G., Wilman, A. (2012). Quantitative high-field imaging of sub-cortical gray matter in multiple sclerosis. Mult Scler, 18(4), 433-441. doi: 10.1177/1352458511428464.

LeVine, S., Chakrabarty, A. (2004). The role of iron in the pathogenesis of experimental allergic encephalomyelitis and multiple sclerosis. Ann NYAS, 1012, 252-266. doi: 10.1196/annals. 1306.021.

Lowell, W., Davis, G. Jr. (2008). The light of life: Evidence that the sun modulates human lifespan. Med Hypotheses, 70(3), 501-507.

Lupke, M., Frahm, J., Lantow, M. et al. (2006). Gene expression analysis of ELF-MF exposed human monocytes indicating the involvement of the alternative activation pathway. Biochim Biophys Acta, 1763(4), 402412. doi: 10.1016/j.bbamcr.2006.03.003.

Muehsam, D., Ventura, C. (2014). Life rhythm as a symphony of oscillatory patterns: electromagnetic energy and sound vibration modulates gene expression for biological signaling and healing. Glob Adv Health Med, 3(2), 40-55. doi: 10.7453/gahmj.2014.008.

Mulligan, B., Hunter, M., Persinger, M. (2010). Effects of geomagnetic activity and atmospheric power variations on quantitative measures of brain activity: replication of the Azerbaijani studies. Advances in Space Research, 45, 940-948.

Nance, D., Sanders, V. (2007). Autonomic innervation and regulation of immune system (1987-2007). Brain Behav Immun, 21(6), 736-745. 
Novik, O., Smirnov, F. (2013). Geomagnetic storm decreases coherence of electric oscillations of human brain while working at the computer. Biofizika, 58(3), 554-560.

Palmer S., Rycroft M., Cermack M. (2006). Solar and geomagnetic activity, extremely low frequency magnetic and electric fields and human health at the Earth's surface. Surv Geophys, 27, 557-95. doi: 10.1007/s10712-006-9010-7.

Pinchuk, V., Gluzman, D. (1990). Immunocytochemi and Monoclonal Antibodies in Onkohematology (in Russian). Kyiv. Naukova dumka, $230 \mathrm{p}$.

Popovych, I., Gozhenko, A., Zukow, W., Polovynko, I. (2020). Variety of Immune Responses to Chronic Stress and their Neuro-Endocrine Accompaniment. Scholars' Press. Riga, 172 p. doi http://dx.doi.org/10.5281/zenodo.3822074.

Popovych, I., Lukovych, Yu., Korolyshyn, T., Barylyak, L., Kovalska, L., Zukow, W. (2013). Relationship between the parameters heart rate variability and background EEG activity in healthy men. Journal of Health Sciences, 3(4), 217-240.

Popovych, I., Kozyavkina, O., Kozyavkina, N., Korolyshyn, T., Lukovych, Yu., Barylyak, L. (2014). Correlation between Indices of the Heart Rate Variability and Parameters of Ongoing EEG in Patients Suffering from Chronic Renal Pathology. Neurophysiology, 46(2), 139-148.

Popovych, I., Kul'chyns'kyi, A., Korolyshyn, T., Zukow, W. (2017). Interrelations between changes in parameters of HRV, EEG and cellular immunity at patients with chronic pyelonephritis and cholecystitis. Journal of Education, Health and Sport, 7(10), 11-23.

Popovych, I., Kul'chyns'kyi, A., Gozhenko, A., Zukow, W., Kovbasnyuk, M., Korolyshyn, T. (2018). Interrelations between changes in parameters of HRV, EEG and phagocytosis at patients with chronic pyelonephritis and cholecystitis. Journal of Education, Health and Sport, 8(2), 135-156.

Pulkkinen, T., Tanskanen, E., Viljanen, A. et al. (2011). Auroral electrojets during deep solar minimum at the end of solar cycle 23. J Geophys Res Space Phys, 116, A04207. doi: 10.1029/2010 JA016098.

Rajaram, M., Mitra, S. (1981). Correlation between convulsive seizure and geomagnetic activity. Neurosci Lett, 24(2), 187-191.

Remans, P., van Oosterhout, M., Smeets, T. et al. (2005). Intracellular free radical production in synovial T lymphocytes from patients with rheumatoid arthritis. Arthritis Rheum, 52, 2003-2009. doi: 10.1002/art.21111.

Sajedi, S., Abdollahi, F. (2012). Geomagnetic disturbances may be environmental risk factor for multiple sclerosis: an ecological study of 111 locations in 24 countries. BMC Neurol, 12, 100. doi: 10.1186/1471-2377-12-100.

Sajedi, S., Abdollahi, F. (2017). Which Environmental Factor Is Correlated with Long-Term Multiple Sclerosis Incidence Trends: Ultraviolet B Radiation or Geomagnetic Disturbances? Mult Scler Int, 2017, 4960386. doi: $10.1155 / 2017 / 4960386$.

Simko, M., Mattsson, M. (2004). Extremely low frequency electromagnetic fields as effectors of cellular responses in vitro: possible immune cell activation. J Cell Biochem, 93(1), 83-92. doi: $10.1002 / j \mathrm{cb} .20198$.

Stoupel, E. (2002). The effect of geomagnetic activity on cardiovascular parameters. Biomed Pharmacother, 56(Suppl 2), 247-256.

Stoupel, E., Petrauskiene, J., Abramson, E., Kalediene, R., Sulkes, J. (2002). Distribution of monthly deaths, solar (SA) and geomagnetic (GMA) activity: their interrelationship in the last decade of the second millennium: the Lithuanian study 1990-1999. Biomed Pharmacother, 56(Suppl 2), 301-308.

Thayer, J., Sternberg, E. (2010). Neural aspects of immunomodulation: Focus on the vagus nerve. Brain Behav Immun, 24(8), 1223-1228.

Tracey, K. (2007). Physiology and immunology of the cholinergic antiinflammatory pathway. J Clin Invest, 117(2), 289-296.

Vencloviene, J., Babarskiene, R., Slapikas, R., Sakalyte, G. (2013). The association between phenomena on the sun, geomagnetic activity, meteorological variables, and cardiovascular characteristic of patients with myocardial infarction. Int J Biometeorol, 57(5), 797-804.

Vencloviene, J., Babarskiene, R., Milvidaite, I., Kubilius, R., Stasionyte, J. (2014). The effect of solargeomagnetic activity during and after admission on survival in patients with acute coronary syndromes. Int J Biometeorol, 58(6), 1295-1303. doi: 10.1007/s00484-013-0725-0.

Walleczek, J. (1992). Electromagnetic field effects on cells of the immune system: the role of calcium signaling. FASEB J, 6(13), 3177-3185.

Wing, S. Rider, L., Johnson, J. et al. (2015). Do solar cycles influence giant cell arteritis and rheumatoid arthritis incidence? BMJ Open, 5(5), e006636. doi: 10.1136/bmjopen-2014-006636. 
Zaporozhan, V., Ponomarenko, A. (2010). Mechanisms of geomagnetic field influence on gene expression using influenza as a model system: basics of physical epidemiology. Int J Environ Res Public Health, 7(3), 938-965. doi: 10.3390/ijerph7030938.

Zhadin, M. (2001). Review of russian literature on biological action of DC and low-frequency AC magnetic fields. Bioelectromagnetics, 22(1), 27-45. doi: 10.1002/1521-186x(200101)22:1<27:aid-bem4> 3.0.co;2-2. 